\title{
TRANSIENT AND PERSISTENT COST EFFICIENCY IN HOTELS IN THE CANARY ISLANDS
}

\author{
Jorge V. Pérez-Rodríguez iD \\ Eduardo Acosta-González \\ University of Las Palmas de Gran Canaria
}

The aim of this study is to determine the presence or otherwise of transient and/or persistent cost inefficiency in the lodging industry. To do so, we applied the method proposed by Filippini and Greene, within a stochastic frontier panel data framework. Our empirical analysis is based on data for the hotel industry in the Canary Islands (Spain), an important destination for European tourists, for the period 2002-2015. Using a stochastic translog cost frontier model, we show that the industry's real output during the study period could have been achieved at $17 \%$ less cost if persistent (systematic) inefficiency were eliminated, and at $24 \%$ less cost in the absence of transient (nonsystematic) inefficiency. We also present evidence of factors that strongly influence hotels' transient cost efficiency, such as the positive effects of market share (in total revenue terms) and certain management characteristics, including the degree of independence with respect to shareholders, the experience in the industry (years in business) and the number of subsidiaries.

KEYWORDS: Persistent (systematic) and transient (nonsystematic) cost inefficiency; lodging firms; maximum simulated likelihood

\section{INTRODUCTION}

In a competitive market, hotel managers and policy makers need information on the level of cost efficiency in the firm and the industry, respectively. For example, hotel managers might use this information to improve competitiveness by decreasing operating costs, thus achieving resource/cost savings in both the short and the long term, while accurate information on hotel efficiency can help policy makers design an effective policy on subsidies for the industry, for example by providing financial support only if efficiency standards are met (Filippini, Geissmann, et al., 2018).

\footnotetext{
Authors' Note: The views expressed here are those of the authors and not necessarily those of the institution with which they are affiliated.
} 
Various techniques have been proposed for estimating efficiency, mostly based on determining how effectively a hotel is using its resources and on identifying the factors that are beyond the manager's control (Reynolds, 2003). Many studies of hotel efficiency have calculated and analyzed this parameter using data envelopment analysis and/or stochastic frontier (SF) analysis, applied within cross-section and panel data frameworks (see Arbelo, Pérez-Gómez, González-Dávila, et al., 2017; Assaf et al., 2010; Assaf \& Josiassen, 2016; Barros et al., 2009, for an extensive review of the literature in this respect).

Recent developments in the SF panel data approach have enabled policy makers and hotel managers to better assess efficiency in the lodging industry, helping them optimize resources and make appropriate decisions.

Firstly, the traditional SF models have been extended to include firm-specific heterogeneity, to avoid confounding efficiency with unobserved heterogeneity (Greene, 2005a; Tsionas, 2002). Failure to account for this factor in a panel data model might subject it to misspecification bias and produce inconsistent parameter estimates. Specific unobserved heterogeneity could be caused by unobserved technological differences, by variations in hotel characteristics (such as accessibility) or by differences in managers' ability to foster staff productivity. Therefore, inefficiency and unobserved heterogeneity should be modelled separately within the model to distinguish these effects.

Second, to better evaluate efficiency when using SF panel data, the level of production/cost inefficiency can be split into persistent (time-invariant) and transient (time-variant) components (Colombi et al., 2014), each of which has different meanings and economic implications. ${ }^{1}$ According to Filippini, Geissmann, et al. (2018), the transient component represents inefficiencies that vary over time, such as nonsystematic and singular management errors. In the short and medium term, firms normally focus on improving transient inefficiencies. Persistent inefficiency, on the other hand, could be due to recurrent management errors, structural problems affecting the provision of services or cost processes, or long-term factor misallocations. If such problems could be resolved, this would alleviate the persistent element of the inefficiencies experienced. Failure to take them into account could reduce overall efficiency and might invalidate the policy measures adopted. Accordingly, the analyst must jointly consider all sources of overall efficiency, that is, both persistent and transient efficiencies, to ensure the resulting model does not produce a biased estimate of overall inefficiency, especially if persistent inefficiency and/or unobserved heterogeneity are present (Colombi et al., 2014). If these two efficiencies were omitted from the analysis, it might be impossible to formulate effective policy measures. In this respect, Filippini, Greene, et al. (2018) developed a theoretical model that highlighted the difference between persistent and transient inefficiency in the application of a price-cap regulation method. The potential existence of persistent efficiency raises questions about the effectiveness of any price-cap regulation that does not distinguish the two components of 
efficiency. As Filippini's theoretical model suggests, when persistent and transient efficiencies are not estimated correctly, the regulator may address or impose inappropriate efficiency targets.

To our knowledge, previous empirical studies of hotel efficiency conducted using SF panel data models have not explicitly distinguished between transient and persistent inefficiencies, with a few recent exceptions related to other (nonhospitality) industry sectors (e.g., Colombi et al., 2017, for hospitals; Filippini, Geissmann, et al., 2018; Filippini, Greene, et al., 2018, for electricity distribution; Agasisti \& Gralka, 2019, for universities). Most such models have focused either on time-invariant or time-variant inefficiency, without separating them from unobserved heterogeneity. Some empirical studies of hotel efficiency have estimated the persistent part of efficiency, but with irregular levels of accuracy, while others have examined only the transient component. Thus, some papers have focused on time-invariant hotel inefficiency (Chen, 2007), while others have estimated time-varying inefficiency, using the Battesse and Coelli (1992) model (Barros, 2004; Kim, 2011). Other researchers have examined time-varying inefficiencies using the Battesse and Coelli (1992) model in a Bayesian framework (Assaf \& Magnini, 2012), or time-varying efficiency, assuming the mean level of inefficiency to be a function of exogenous variables, using the Battesse and Coelli (1995) model (Arbelo, Pérez-Gómez, \& Arbelo-Pérez, 2017, Arbelo, Pérez-Gómez, González-Dávila, et al., 2017; Pérez-Rodríguez \& Acosta-González, 2007). The results obtained in these research projects provide interesting insights regarding overall hotel efficiency and its determinants. However, they do not explicitly account for unobserved heterogeneity. To address this shortcoming, several authors have separated unobserved heterogeneity from efficiency. For example, Barros et al. (2010) used the random coefficient model of Greene (2005a) in this respect, while Assaf and Tsionas (2018) analyzed both heterogeneity and time-varying efficiency and proposed a new, flexible Bayesian framework for this purpose. Finally, Arbelo et al. $(2020,2021)$ separated specific inefficiencies from technological heterogeneity using the random coefficient model of Tsionas (2002) within a Bayesian framework.

Despite the wide range of approaches described above, in the above-cited papers overall hotel efficiency is estimated without distinguishing between transient and persistent efficiency, as noted by Colombi et al. (2014) and Filippini and Greene (2016).

Our article makes a novel contribution to the empirical literature on hotel efficiency in two ways. On the one hand, we incorporate recent advances in the econometric estimation of efficiency based on panel data specification and estimation, separating persistent and transient efficiencies from unobserved heterogeneity. Our simultaneous estimation of the levels of persistent and transient efficiency is based on a four-component SF panel data model, termed the generalized true random effect (GTRE) model. ${ }^{2}$ This model, which was introduced by Colombi et al. (2011; Colombi et al., 2014) and refined by Kumbhakar et al. 
(2014), has also been employed by Filippini and Greene (2016), using maximum simulated likelihood. ${ }^{3}$

On the other hand, we provide empirical evidence regarding the existence of both types of inefficiencies and of unobserved heterogeneity, using a stochastic translog cost frontier panel data model, based on data obtained from the lodging industry in the Canary Islands (Spain). From the proposed model, we also estimate the technological change (TC) and the return to scale (RTS). We focus on the lodging industry in the Canary Islands in particular for the following reasons: first, unlike all other "sun and beach" tourist destinations in Spain, which present a markedly seasonal behavior pattern, tourist arrivals in the Canary Islands are evenly distributed throughout the year. Second, the tourism sector is the most important source of income for this region, accounting for $30 \%$ of its GDP in 2017. Finally, the Canary Islands is the third most important Spanish region in terms of tourist arrivals (mainly from Germany, the United Kingdom, and mainland Spain). In this analysis, we examine annual panel data for a sample of hotels for the 14 years from 2002 to 2015, an extensive period that included the economic and financial crisis that started in 2007. This focus enables us to analyze the time path of hotel efficiency and the effects of the crisis on the industry.

The rest of this article is structured as follows: First, the following section briefly outlines the situation of the Canary Islands hotel industry. Second, we review the literature on the question of hotel efficiency and describe the SF models used to determine hotel efficiency in the context of transient and persistent efficiency. Third, we describe the SF model that Filippini and Greene (2016) employed to determine cost efficiency in the context of unobserved heterogeneity. In this analysis, we distinguish transient from persistent efficiency. Fourth, the study data considered and the results derived from our empirical analysis. Finally, the main conclusions drawn are summarized.

\section{THE LODGING INDUSTRY IN THE CANARY ISLANDS}

The Canary Islands region of Spain is an archipelago formed by Gran Canaria, Lanzarote, Fuerteventura, Tenerife, La Palma, Gomera, and Hierro. It is a major national and international tourist destination, thanks to its many excellent beaches, attractive landscape, climate, sports facilities, and other cultural and tourist attractions. With respect to tourism, the most important islands are Tenerife, Gran Canaria, Lanzarote, and Fuerteventura.

The tourism industry is a source of foreign exchange earnings and stimulates investment in physical and human capital, underpinning economic growth in the Canary Islands, creating jobs, generating income, boosting consumption and tax revenues, and thus indirectly promoting public spending. In 2017, the tourism industry accounted for $30 \%$ of the region's GDP, over $30 \%$ of employment, $30 \%$ of tax revenue, and $8 \%$ of public expenditure (Instituto Nacional de Estadística, 2017). 
Although tourism has been a major industry in the Canary Islands for more than 40 years, visitor numbers are still rising. One reason for this is that, unlike all other "sun and beach" tourist destinations in Spain, which present a markedly seasonal behavior pattern, tourist arrivals in the Canary Islands are evenly distributed throughout the year. As a result, the islands constitute the third most important Spanish region in terms of tourist arrivals. In 2017, the islands received 14.2 million international tourists, mainly from Europe, especially Germany, United Kingdom, mainland Spain and Sweden (FRONTUR, 2017). Annual tourist spending in the region has been estimated at 16.6 billion euros and the lodging industry accounts for 100 million overnight stays (Instituto Canario de Estadística, 2017).

The Canary Islands lodging industry is diverse, but establishments can basically be classed as hotels or extra-hotels. ${ }^{4}$ In response to rising demand, many establishments have sought to raise efficiency, for example, by increasing occupancy rates and tariffs. Consequently, 2015 was a record year for the sector, with hotel profits rising by $17.7 \%$ (Christie \& Co, 2016) and extrarevenue streams being added throughout the sector. Moreover, employment levels rose more strongly than in any other economic sector in the region (Inchausti-Sintes \& Voltes-Dorta, 2020). A relevant factor in this favorable outcome was the regional government's 2001 moratorium on the construction of tourist accommodation. Only five-star "grand luxury" hotels were exempted from the restrictions of the law. ${ }^{5}$ As a result, the supply of high-quality accommodation has increased significantly in the past 20 years, with big-spending five-star tourists accounting for a larger share of the market and producing significant economic benefits for the islands (Inchausti-Sintes \& Voltes-Dorta, 2020). In this respect, Tzeremes (2019) and Sellers-Rubio and Casado-Díaz (2018) observed sharp rises in hotel efficiency in the Canary Islands between 2008 and 2016.

Supplemental Table S1 (available online) describes various aspects of hotel capacity in the Canary Islands in recent years (Instituto Canario de Estadística, 2017). In general, the pattern of lodging supply remained unchanged during the period considered. By star rating, the majority of hotels in the archipelago were four-star, followed by those in the three-star category. Investment activity in this sector is dominated by domestic investors, although some European investment is also present. In Spain, the islands attracted 28\% of total investment in 2015 and accounted for 33.2\% of total hotel rooms (Christie \& Co, 2016).

\section{LITERATURE REVIEW OF TRANSIENT AND PERSISTENT EFFICIENCY MODELLING}

This section focuses on SF analysis, in which panel data models are used to separate persistent and transient efficiencies in general econometric modelling. Models of time-varying inefficiency have been proposed by Cornwell et al. (1990) and Lee and Schmidt (1993). Kumbhakar (1990) described a flexible 
model, and Battese and Coelli $(1992,1995)$ presented time decay and inefficiency effects models. In this respect, Greene (2005a, 2005b) considered two models, true fixed effects and TRE, each of which included a transient inefficiency term and assumed unobserved unit-specific heterogeneity.

A feature common to these time-varying SF models is that they do not take separate account of the persistent and the transient parts of inefficiency. In some cases, time-invariant inefficiency and time-invariant heterogeneity are merged into a single term, despite the distortion this may introduce. In this respect, unitspecific unobserved heterogeneity can be interpreted as persistent inefficiency (Kumbhakar, 1991; Kumbhakar \& Heshmati, 1995; Kumbhakar \& Hjalmarsson, 1993, 1995) or as the consequence of firm effects. Other researchers, such as Pitt and Lee (1981) and Schmidt and Sickles (1984), have addressed only the persistent aspect of inefficiency. In other cases (Battese \& Coelli, 1992, 1995; Cornwell et al., 1990; Greene, 2005a, 2005b; Kumbhakar, 1990), only the transient effect of inefficiency is analyzed. To overcome this problem of limited focus, in which only the transient part of efficiency is considered, Colombi et al. (2014) and Tsionas and Kumbhakar (2014) took a step further, dividing the time-invariant error term into two, with one element reflecting firms' latent heterogeneity (Greene, 2005a, 2005b) and the other, their persistent (long-run) inefficiency (Kumbhakar \& Heshmati, 1995; Kumbhakar \& Hjalmarsson, 1993, 1995). As suggested by Tsionas and Kumbhakar (2014), this model is called the generalized TRE (GTRE) model.

The GTRE model is simply a TRE model in which persistent heterogeneity and persistent efficiency are clearly differentiated, with each one presenting a skew-normal distribution, rather than a normal distribution (Colombi et al., 2014). However, these models cannot simultaneously address persistent and transient inefficiencies, unobserved heterogeneity and random shocks. To overcome this shortcoming, Colombi et al. (2014) proposed a four-random-component SF model and a maximum likelihood estimation method. This model was later analyzed by Filippini and Greene (2016), using maximum simulated loglikelihood as an estimation method and characterizing the four-random-component model as a pair of two-part disturbances in which each element of the pair had its own skew-normal distribution. According to these authors, the productive efficiency of a firm specified by a GTRE model is composed of two parts, one that is persistent and another that is transient. In turn, the persistent part has two components. The first reflects the presence of persistent firm-level heterogeneity (not efficiency) and highlights structural problems in the firm's production process. The second represents the presence of persistent firm-level inefficiency, and reveals systematic shortcomings in managerial capabilities. The transient part also has two components, one that captures transient inefficiency, representing the presence of nonsystematic management problems that can be resolved in the short term, while the other is composed of random noise. Filippini and Greene (2016) developed a practical full-information maximum 
simulated likelihood estimator for the model described by Colombi et al. (2014), to estimate the persistent and transient inefficiency terms, thus extending the TRE model. Among the very few empirical papers to have analyzed the distinction between transient and persistent inefficiency are Colombi et al. (2017), with respect to hospitals, Filippini, Geissmann, et al. (2018; Filippini, Greene, et al., 2018), for electricity distribution, and Agasisti and Gralka (2019), on universities. Colombi et al. (2017) extended the GTRE model by including exogenous determinants of Italian hospital persistent (long-run) and transient (short-run) inefficiency, separated from unobserved heterogeneity, during the period 20082013. These authors concluded that transient efficiency is more important than persistent efficiency, among other results. Filippini, Geissmann, et al. (2018) applied the GTRE model to a total cost function for Swiss hydropower firms in the period 2000-2013, observing that both transient and persistent cost inefficiencies were present.

The question of efficiency in the hotel industry has received significant research attention using nonparametric and parametric methods (see Assaf \& Josiassen, 2016; Assaf \& Tsionas, 2018, for excellent overviews). However, most studies based on parametric methods only estimate the transient part of efficiency, using Battese and Coelli's (1992) model (e.g., Barros, 2004; Kim, 2011) or Battese and Coelli's (1995) panel data models (Arbelo, Pérez-Gómez, \& Arbelo-Pérez, 2017; Arbelo, Pérez-Gómez, González-Dávila, et al., 2017) or both (Pérez-Rodríguez \& Acosta-González, 2007). Each of these models is used in conjunction with the cost translog frontier model. Finally, some papers attempt to account for unobserved heterogeneity without distinguishing between persistent and transient efficiencies (Arbelo et al., 2020, 2021; Assaf \& Tsionas, 2018; Barros et al., 2010).

To our knowledge, however, no empirical studies of hotel efficiency have distinguished between persistent and transient efficiencies, while also considering their combined effect. In this article, therefore, our aim is to analyze and quantify the joint impacts of transient and persistent hotel cost efficiency. This approach avoids the problems of bias that can arise when the parameters are estimated separately and enables us to distinguish between nonsystematic hotel management problems, which can be addressed and overcome in the short term, from systematic managerial shortcomings or structural problems.

\section{A TRANSLOG STOCHASTIC COST FRONTIER GTRE MODEL}

The following expression represents the general specification for our translog stochastic cost frontier (SCF) model, based on a GTRE panel data model for multiple production and incorporating Hicksian neutral technological progress, expressed by the linear trend and cross-products, together with other explanatory variables (input prices and outputs) and squared time trends: 


$$
\begin{aligned}
& \log c_{i t}= \alpha+\left(\omega_{i}-h_{i}\right)+\sum_{m=1}^{M} \beta_{m} \log y_{m, i t}+\sum_{k=1}^{K} \alpha_{k} \log w_{k, i t} \\
&+\frac{1}{2} \sum_{m=1}^{M} \sum_{k=1}^{M} \varphi_{m k} \log y_{m, i t} \log y_{k, i t}+\frac{1}{2} \sum_{k=1}^{K} \sum_{j=1}^{K} \pi_{k j} \log w_{k, i t} \log w_{j, i t} \\
&+\sum_{m=1}^{M} \sum_{k=1}^{K} \eta_{m k} \log w_{k, i t} \log y_{m, i t} \\
&+\kappa_{1} t+\kappa_{2} t^{2}+\sum_{k=1}^{K} \rho_{k} \log w_{k, i t} t+\sum_{m=1}^{M} \tau_{m} \log y_{m, i t} t+\left(v_{i t}+u_{i t}\right) \\
& \omega_{i} \sim N\left(0, \sigma_{\omega}^{2}\right) \\
& h_{i}=\left|H_{i}\right|, H_{i} \sim N\left(0, \sigma_{h}^{2}\right) \\
& v_{i t} \sim N\left(0, \sigma_{v}^{2}\right) \\
& u_{i t} \sim N^{+}\left(0, \sigma_{u}^{2}\right)
\end{aligned}
$$

where $\log$ is the natural logarithm, $i=1,2, \ldots, n$ is the number of hotels, $t=1,2, \ldots, T_{i}$ is the number of time periods (which may vary for each hotel), $c_{i t}$ is the cost of firm $i$ in period $t ; w_{j, i t}$ is the $j$-th input price and $y_{m, i t}$ is the $m$-th production of hotel $i$ in period $t$ (level, squares and cross products); the vector of unknown parameters is as follows:

$$
\Omega=\left[\begin{array}{llllllllll}
\alpha & \beta_{m} & \alpha_{k} & \varphi_{m k} & \pi_{k j} & \eta_{j m} & \kappa_{1} & \kappa_{2} & \rho & \tau_{m}
\end{array}\right]
$$

Finally, $\omega_{i}$ and $h_{i}$ represent the time-invariant disturbance, where $\omega_{i}$ is the specific unobserved heterogeneity, which is normally distributed with zero mean and $\sigma_{\omega}^{2}$ variance; $h_{i}$ is a RE, which represents the time-invariant persistent inefficiency of hotel $i$, and where $h_{i}=\left|H_{i}\right|$ and $H_{i}$ are distributed normally with zero mean and variance $\sigma_{h}^{2}$, while $\left(\omega_{i}-h_{i}\right)$ follows a skew-normal distribution with parameters $\gamma=\sigma_{h} / \sigma_{\omega}$ and $\theta=\left(\sigma_{\omega}^{2}+\sigma_{h}^{2}\right)^{1 / 2}$. On the other hand, $u_{i t}$ and $v_{i t}$ represent the time-varying disturbance, $\varepsilon_{i t}=\left(v_{i t}+u_{i t}\right)$, where $u_{i t}$ captures the time-varying efficiency, which is distributed as $N^{+}\left(0, \sigma_{u}^{2}\right)$ and where $v_{i t}$ is a symmetric disturbance representing the random noise, which is assumed to be iid $N\left(0, \sigma_{v}^{2}\right)$, and independent of $u_{i t}$, while $\varepsilon_{i t}$ follows a skew-normal distribution with parameters $\lambda=\sigma_{u} / \sigma_{v}$ and $\sigma=\left(\sigma_{v}^{2}+\sigma_{u}^{2}\right)^{1 / 2}$.

The GTRE model can be estimated by maximum likelihood. However, as there is no closed form for the density of the compound disturbance term, $\varepsilon_{i t}$, we perform this estimation by maximum simulated likelihood (MSL).

The logarithm of likelihood can be written as follows: 


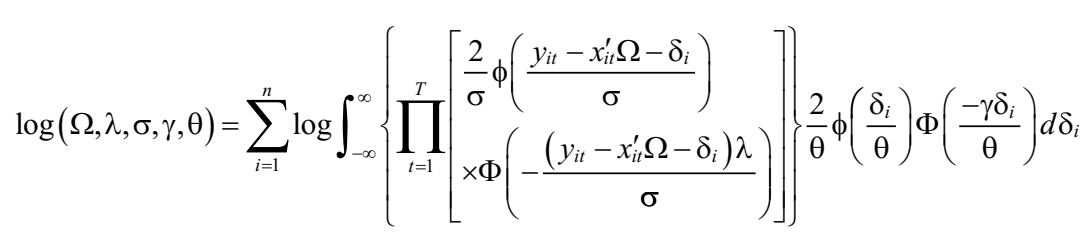

where $x_{i t}^{\prime}$ is a row vector of explanatory variables of firm $i$ at moment $t$ with one in its first element to take into account the constant of the model. Moreover, $\phi$ is the standard normal density, $\Phi$ is the standard normal cdf and $\varepsilon_{i t}=y_{i t}-x_{i t}^{\prime} \Omega$. Finally, $\omega_{i}=\sigma_{\omega} W_{i}$, where $W_{i}$ is normally distributed with mean zero and variance one, and $\delta_{i}=\sigma_{\omega} W_{i}-\sigma_{h}\left|H_{i}\right|$. The integral does not exist in closed form, and therefore it can be evaluated by simulation. The simulated log likelihood is expressed by:

$$
\log \left(\Omega, \lambda, \sigma, \sigma_{\omega}, \sigma_{h}\right)=\sum_{i=1}^{n} \log \frac{1}{R} \sum_{r=1}^{R}\left\{\prod_{t=1}^{T}\left[\begin{array}{l}
\frac{2}{\sigma} \phi\left(\frac{y_{i t}-x_{i t}^{\prime} \Omega-\delta_{i r}}{\sigma}\right) \\
\times \Phi\left(-\frac{\left(y_{i t}-x_{i t}^{\prime} \Omega-\delta_{i r}\right) \lambda}{\sigma}\right)
\end{array}\right]\right\}
$$

where $\delta_{i r}=\sigma_{\omega} W_{i r}-\sigma_{h}\left|H_{i r}\right|$, and $W_{i r}$ and $H_{i r}$ are both normally distributed with zero mean and variance one. $W_{i r}$ and $H_{i r}$ are $R$ simulated draws from the standard normal population, using Halton or generalized Halton sequences. The resulting random variables for $\left(\omega_{i}-h_{i}\right)$ and $\left(v_{i t}+u_{i t}\right)$ in model [1] are closed skew-normal distributions, not normal distributions.

The GTRE estimator creates two new variables, the transient efficiency estimator, $E\left[u_{i t} / \varepsilon_{i t},\left(\omega_{i}-h_{i}\right)\right]$, which allows us to estimate transient efficiency, and $E\left[h_{i} / \varepsilon_{i t},\left(\omega_{i}-h_{i}\right)\right]$, which allows us to estimate persistent efficiency.

Following Colombi et al. (2014), some restrictions can be imposed on the general form defined by equation [1] to test for alternative models. For example, if $\sigma_{h}^{2}=0$ we have the TRE model of Greene (2005a, 2005b), in which all the inefficiency is time varying, and so there is no persistent counterpart. However, if the restriction is false $\left(\sigma_{h}^{2} \neq 0\right)$, and even so, a TRE model is estimated, any time-invariant or persistent component of inefficiency is completely absorbed within the individual-specific constant term, and it is impossible to distinguish between heterogeneity and inefficiency. On the other hand, if $\sigma_{\omega}^{2}=0$ we have the Kumbhakar and Heshmati (1995) model, which accommodates both transient and persistent inefficiencies but not heterogeneity. Another possibility is that $\sigma_{h}^{2}=0, \sigma_{\omega}^{2}=0$ and the inefficiency term $u_{i t}$ is then assumed to be constant over time $\left(u_{i t}=u_{i}\right)$. In this case, we have the classical SF RE model (Pitt \& Lee, 1981). 
Table 1

Characteristics of Inputs, Outputs, and Covariates in the Period 2002-2015

\begin{tabular}{lcc}
\hline Variables & $M$ & $S D$ \\
\hline Full-time employees & 122.8 & 131.1 \\
Labor price & 63.22 & 501.52 \\
Capital price & 0.064 & 0.205 \\
Operating costs & $9,715.6$ & $10,197.0$ \\
Total revenue & $10,078.1$ & $11,896,5$ \\
Market share & $0.95 \%$ & $1.12 \%$ \\
Number of subsidiaries & 1.0339 & 1.96 \\
Experience (years in business) & 18.3415 & 11.34 \\
Degree of independence (1= total or direct & 0.8534 & - \\
$\quad$ ownership of one shareholder greater than 50\%) & & - \\
Crisis period (1=2007-2008) & 0.1436 & - \\
\hline
\end{tabular}

Note: Descriptive statistics are reported for the pooled sample. All monetary values are in thousands of euros.

\section{EMPIRICAL ANALYSIS}

\section{Data}

The data analyzed were obtained from the Iberian Balance Sheets Analysis System (Bureau van Dijk or BvD), in its annual reports from 2002 to 2015, containing information on inputs and outputs. From this database, we initially selected 341 companies operating in the Canary Islands in the tourist accommodation sector (according to Category 5510 of the National Classification of Businesses, CNAE-93, which covers the exploitation and management of hotels and similar activities) with an operating annual revenue greater than 500,000 euros in at least 1 of the years considered and more than 10 employees in 2015. However, many of these companies were subsequently eliminated from the study because they managed not only hotels but also apartments. This circumstance was confirmed by examination of the corporate website. After this filtering process, 127 companies remained in the final sample.

Cost frontiers were estimated using unbalanced panel data. Table 1 shows the descriptive characteristics of the study variables, with information on the respective inputs and outputs. In line with Pérez-Rodríguez and Acosta-González (2007), depending on data availability, inputs were measured according to labor expenses (number of full-time equivalent workers and the corresponding costs) and capital expenses. From these variables, the unit prices of labor and capital were obtained. Output was measured by total operating revenue. For the period 2002 to 2015 , monetary values are presented in thousands of euros, according to the base 2016 consumer price index. The unbalanced panel data were composed of 1,778 observations.

In addition, we considered certain environmental factors which can affect hotel efficiency, such as hotel size, the degree of managerial independence from 
shareholders, and hotel location (Assaf et al., 2010). To evaluate the heterogeneity of hotel efficiencies, we included a proxy for size, namely the market share of each hotel in the area considered. For each hotel and year, the market share (MS) was calculated as follows:

$$
M S_{i t}=\frac{T \times R_{i t}}{\sum_{i=1}^{N} \sum_{t=1}^{T} R_{i t}}, \quad i=1,2, \ldots, N, \quad t=1,2, \ldots, T
$$

where $R_{i t}$ represents the total operating revenue of hotel i at moment $\mathrm{t}$, and $\mathrm{T}$ and $\mathrm{N}$ are the number of years and the number of hotels, respectively (the result is multiplied by $\mathrm{T}$ to obtain the annualized figure).

The other source of heterogeneity among the hotels analyzed is the degree of independence of managers from the firm's shareholders. BvD has created an independence indicator which classifies companies into categories A, B, C, D, or $\mathrm{U}$, with further qualifications. Category $\mathrm{A}$ is assigned to any company with known recorded shareholders none of whom has more than $25 \%$ (direct or total) ownership of the company. Category B describes any company with known recorded shareholders none of whom has more than 50\% ownership (direct, total, or calculated total), but where one or more shareholders has at least $25 \%$ ownership. Category $\mathrm{C}$ refers to any company with at least one recorded shareholder whose total or calculated total ownership is over $50 \%$. In addition, the qualification $\mathrm{C}+$ is attributed to Category $\mathrm{C}$ companies in which the sum of direct ownerships (including all categories of shareholders) is $50.01 \%$ or higher. Such a company cannot be considered Category D, which excludes any company that has an unknown direct shareholder with $50.01 \%$ or more of the ownership. Category $\mathrm{C}$ is also assigned to a company when it has an ultimate owner whose percentage of ownership is unknown. Category D is allocated to any company which has a recorded shareholder with a direct ownership share of over $50 \%$. Subsidiaries and foreign-owned companies are also classed as D. Finally, Category $\mathrm{U}$ is allocated to companies that do not correspond to any of the above categories, thus indicating an unknown degree of independence (however, none of the hotels in our sample belonged to this category). Considering these indicators, we created a dummy variable taking the value 1 if the hotel belonged to Category $\mathrm{C}, \mathrm{C}+$, or $\mathrm{D}$, that is, when there existed a relationship of dependence between the firm's managers and shareholders, and zero otherwise.

Another variable that may influence hotel efficiency is the influence of the recent financial and economic crisis. This variable could be relevant because hotels' adjustments during this period, for example, hiring and firing, and/or pricing adjustments (e.g., retaining only the least costly elements) may have affected their efficiency. To reflect these considerations, we included a dummy variable taking the value 1 if an observation corresponded to the crisis period (2007-2008) and zero otherwise. In addition, we took into account the hotel's experience, i.e. its ability (unobserved factor) to remain in the market. This variable allowed us to evaluate the question of learning-by-doing, that is, the 
learning curve, and is quantified as the number of years the hotel has been running. ${ }^{6}$ The final variable considered is the number of subsidiaries controlled by the hotel company.

\section{Estimation Results for Transient and Persistent Inefficiencies}

To estimate the cost function in equation [1], we consider, firstly, the input prices, that is, the variables associated with operating costs (materials, labor, space, and information systems). To do so, we take $n=127$ (sample size), $M=1$ (outputs), and $K=2$ (price of inputs; labor and capital), with $y_{1}$ representing the total revenue. Then, we impose the symmetry restrictions $\left(\varphi_{m k}=\varphi_{k m}\right.$ and $\pi_{k j}=\pi_{j k}$ ), and the condition that the cost function should be homogeneous of degree one in prices (in other words, the increase in total cost is proportional to that of the individual prices, for a given output). Therefore, cost and input prices are normalized by $w_{K, i t}$ (i.e., the numerator) to impose homogeneity restrictions. The price of labor is taken as the numerator. Hence, the price of capital is divided by the price of labor, that is, $w_{2} / w_{1}$. Finally, the cost frontier model also incorporates time trends, cross-products with the remaining variables and the dichotomous variable. Together, these considerations enable us to evaluate the effect of the crisis period.

This article considers three SF models. Two are traditional and the third was proposed more recently. The first is the basic version of the RE model proposed by Pitt and Lee (1981); the second is the TRE model proposed by Greene (2005a, 2005b); the third is the GTRE model introduced by Colombi et al. (2014) and Filippini and Greene (2016).

Table 2 shows the maximum likelihood parameter estimates obtained, with the corresponding $p$ values, for the SF equation [1] in the cases of the RE, TRE, and GTRE models. These models present the following characteristics:

1. The RE model produces cost efficiency values that are time invariant and therefore reflect the persistent part of the firm's cost efficiency. For this model $\omega_{i}$ and $h_{i}$ are absent from equation [1] and $u_{i t}=u_{i}$.

2. The TRE model produces values that are time varying and therefore reflect the transient part of the cost efficiency. ${ }^{7}$ In this case, $h_{i}$ is absent from equation [1].

3. The GTRE model introduces the possibility of estimating the persistent and the transient parts of cost inefficiency concurrently. This model coincides with equation [1]. In estimating the GTRE model, the simulation process was based on 250 Halton draws.

Table 2 also includes the logarithm of the maximum likelihood ( $\log \mathrm{L})$, the number of hotels, total panel observations and measures of TC and RTS, which are functions of the parameters and data considered, and descriptive statistics for estimated cost efficiency scores. These measures are calculated following Kumbhakar et al. (2013) and are defined as follows: TC is the rate of change in 
Table 2

Panel Data Estimates Without Covariates for Mean Inefficiency, Using the Translog Cost Stochastic Frontier Model: Unbalanced Panel Data (2002-2015)

\begin{tabular}{|c|c|c|c|c|c|c|}
\hline \multirow[b]{2}{*}{ Variables } & \multicolumn{2}{|l|}{$\mathrm{RE}$} & \multicolumn{2}{|l|}{ TRE } & \multicolumn{2}{|l|}{ GTRE } \\
\hline & Coeff. & $p$ & Coeff. & $p$ & Coeff. & $p$ \\
\hline \multicolumn{7}{|l|}{ Translog cost frontier } \\
\hline $\log w_{2} / w_{1}$ & 0.2702 & .82 & $-1.0103^{* \star *}$ & .00 & $0.32278^{* \star *}$ & .00 \\
\hline $0.5 \times\left(\log w_{2} / w_{1}\right)^{2}$ & -0.9303 & .15 & $-0.1456^{* * *}$ & .00 & $0.01172^{* * * *}$ & .00 \\
\hline $\log y_{1}$ & $-6.2588^{\star * *}$ & .00 & -0.0441 & .47 & $-0.27748^{* * *}$ & .00 \\
\hline $0.5 \times\left(\log y_{1}\right)^{2}$ & $5.4393^{* * *}$ & .00 & $0.1293^{* * *}$ & .00 & $0.03987^{+* * *}$ & .00 \\
\hline $\log y_{1} \times \log w_{2} / w_{1}$ & $0.7137^{\star \star \star}$ & .00 & $0.0580^{* * *}$ & .00 & 0.00329 & .32 \\
\hline Time & 3.4224 & .44 & $-0.0963^{* * *}$ & .00 & $0.05164^{* * *}$ & .00 \\
\hline time $^{2}$ & -0.1487 & .58 & $-0.0013^{* *}$ & .02 & $-0.00092^{* *}$ & .04 \\
\hline $\log y_{1} \times$ time & 0.6954 & .14 & -0.0005 & .68 & $-0.00436^{* * *}$ & .00 \\
\hline $\log w_{2} / w_{1} \times$ time & 0.9469 & .11 & $-0.0213^{* \star *}$ & .00 & $-0.00316^{* * *}$ & .00 \\
\hline Constant & -137.71 & .88 & 0.1117 & .36 & $4.14638^{* * *+}$ & .00 \\
\hline$\sigma_{u}$ & $0.0017^{* * *}$ & .00 & $0.3072^{a}$ & - & $0.4210^{a}$ & - \\
\hline$\sigma_{v}$ & $160.64^{* * * *}$ & .00 & $0.2372^{a}$ & - & $0.1932^{a}$ & - \\
\hline$\lambda$ & - & - & $1.2951^{* * *}$ & .00 & $2.1789^{* \star \star}$ & .00 \\
\hline$\sigma$ & - & - & $0.3881^{* * *}$ & .00 & $0.4633^{* * *}$ & .00 \\
\hline$\sigma_{w}$ & - & - & $0.3377^{* * *}$ & .00 & $1.5055^{\star \star *}$ & .00 \\
\hline$\sigma_{h}$ & - & - & - & - & $0.2471^{* * *}$ & .00 \\
\hline $\log \mathrm{L}$ & -11553.67 & & -454.51 & & -482.14 & \\
\hline \multicolumn{7}{|l|}{ Average of } \\
\hline $\begin{array}{c}\text { Technological } \\
\text { change (TC) }\end{array}$ & $1.089(1.84)$ & & $0.016(0.02)$ & & $0.020(0.01)$ & \\
\hline $\begin{array}{l}\text { Return to scale } \\
\text { (RTS) }\end{array}$ & $41.642(7.17)$ & & $0.700(0.17)$ & & $0.014(0.05)$ & \\
\hline Number of hotels & 127 & & 127 & & 127 & \\
\hline Total observations & 1,778 & & 1,778 & & 1,778 & \\
\hline
\end{tabular}

Note: log is the natural logarithm. ${ }^{* * *},{ }^{* *}$, and * indicate significance at $1 \%, 5 \%, 10 \%$ level, respectively. Log $L$ is the logarithm of the maximum likelihood function. Total panel observations are the number of effective data used in the estimations. $R E=$ random effect; TRE = true random effect; GTRE = generalized true random effect. aRefers to standard errors that are not computed. Standard errors are shown between parentheses.

cost over time, all else being held constant, that is, $\partial \log c_{i t} / \partial t_{i t}$. A negative value suggests technical progress. RTS, which reflects the proportional increase in costs given an increase in all outputs, is defined as the reciprocal of $\sum_{m} \partial \log c_{i t} / \partial \log y_{m, i t}$. If RTS is less than unity, there are no economies of scale. Concretely, a proportional increase in all outputs produces a more than proportional increase in cost (i.e., the scale of operation is over optimum, and therefore benefits can be gained from contraction). The opposite is true if RTS exceeds unity (economies of scale). The total panel observations are the numbers of 


\section{Figure 1}

Kernel Estimates for Cost Efficiencies Based on the GTRE Model (Closed SkewNormal Frontier Model) and the TRE Model (JLMS): (a) Transient Efficiencies (Time Variant) and (b) Persistent Efficiencies (Time Invariant) in the GTRE Model

(a)

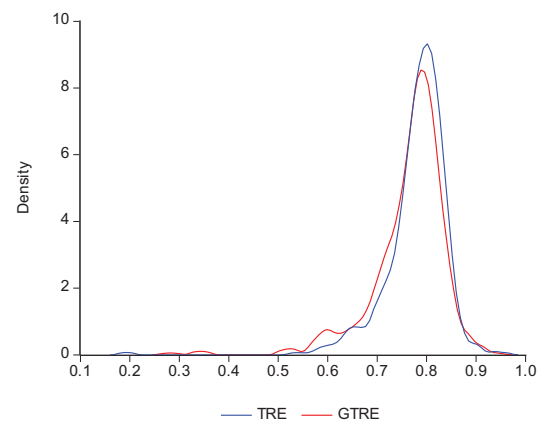

(b)

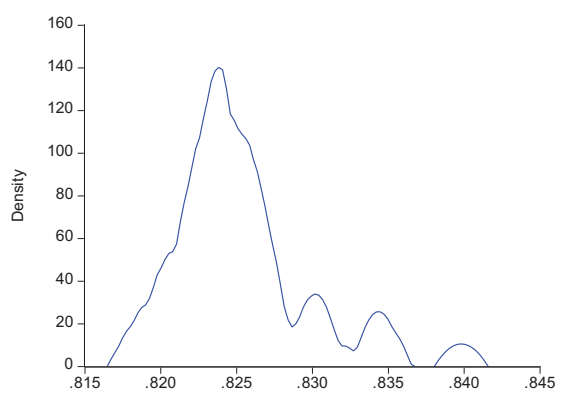

Note: TRE $=$ true random effect; GTRE $=$ generalized true random effect.

effective data used in the estimations. All estimates were obtained by LIMDEP v.11 statistical software.

The likelihood ratio test was performed for the RE, TRE, and GTRE models. The latter was found to best represent the translog cost function, because for all others the hypothesis $\sigma_{h}^{2}=0$ was rejected. Table 2 shows that the coefficients of the GTRE model are significant at $1 \%$ in every case except one, and that the variances $\sigma_{\omega}^{2}$ and $\sigma^{2}$ and the skew-normal distribution parameter $\lambda$ are all statistically significant at $1 \%$, with $\sigma_{u}^{2}$ greater than $\sigma_{v}^{2}$. As aforementioned, the GTRE model makes it possible to distinguish between persistent and transient cost inefficiencies.

Table 2 shows that the GTRE model has a mean RTS value of less than 1 , meaning that economies of scale are not present. However, for the TRE, although the RTS value is less than one the null hypothesis of RTS $=1$ is not rejected. For the RE model, the RTS value is very strange; in our opinion, this must be due to an estimation error or to bias arising from poor specification. Nevertheless, no TC in these models was observed; their coefficients are positive, but do not reach statistical significance.

Figure 1 illustrates the distribution of efficiencies in the TRE and GTRE models, revealing the existence of both types of cost inefficiency in the hotels analyzed. Specifically, Figure 1a shows the kernel density estimates for the transient cost efficiencies (time-varying) estimated by the TRE and GTRE models. As we can see, the two models produce similar estimates in terms of transient efficiency, but the TRE model appears to overestimate the efficiencies, in comparison with the GTRE model. Figure 1b shows the kernel estimates for the persistent efficiency (time-invariant) values estimated by the GTRE model. 
Table 3

Cost Efficiency Scores: 2002-2015

\begin{tabular}{|c|c|c|c|c|}
\hline \multirow[b]{2}{*}{ Cost Efficiency } & \multirow{2}{*}{$\frac{\mathrm{RE}}{\text { Persistent }}$} & \multirow{2}{*}{$\frac{\text { TRE }}{\text { Transient }}$} & \multicolumn{2}{|c|}{ GTRE } \\
\hline & & & Transient & Persistent \\
\hline Mean & 0.6319 & 0.7801 & 0.7632 & 0.8251 \\
\hline Standard deviation & 0.0873 & 0.0627 & 0.0781 & 0.0043 \\
\hline Minimum & 0.2927 & 0.1933 & 0.2818 & 0.8182 \\
\hline $25 \%$ & 0.6158 & 0.7569 & 0.7368 & 0.8228 \\
\hline Median & 0.6687 & 0.7913 & 0.7820 & 0.8243 \\
\hline $75 \%$ & 0.8052 & 0.8169 & 0.8076 & 0.8268 \\
\hline Maximum & 0.9369 & 0.9527 & 0.9367 & 0.8398 \\
\hline Number of hotels & 127 & 127 & 127 & \\
\hline Total observations & 1,778 & 1,778 & 1,778 & \\
\hline
\end{tabular}

Note: Cost efficiency is the cost efficiency expressed as the mean, standard deviation, maximum and minimum, and first, second, and third quantiles $(25 \%$, median and $75 \%$, respectively). Total panel observations are the number of effective data used in the estimations. For the RE and TRE models, cost efficiency estimates are the JLMS estimates. For the GTRE model, we use the expressions proposed by Colombi (2010). $\mathrm{RE}=$ random effect; TRE = true random effect; GTRE = generalized true random effect.

Summarizing our analysis of cost efficiency scores, Table 3 shows descriptive statistics of the estimated levels of cost efficiency. These scores were computed following the approach suggested by Jondrow et al. (1982, JLMS) for the RE and TRE models, and the technical efficiency was computed using the results reported by Colombi (2010), based on the moment generating function for the closed skew-normal distribution. These statistics include the mean, standard deviation, minimum, 1st, 2nd and 3rd quantiles and maximum of the efficiency estimates, which for the case of the GTRE model are distinguished between transient and persistent. Notably, the values for persistent and transient efficiency obtained with the GTRE model differ from those obtained with the RE and the TRE models, which suggests that the efficiency estimates obtained by the RE and the TRE models do not provide accurate information on the levels of persistent and transient efficiency. For example, these patterns differ significantly from those obtained from the RE model, which tend to underestimate the level of persistent efficiency in hotels. As observed by Filippini and Greene (2016), this suggests that the RE results do not correctly reflect firms' persistent efficiency, possibly because in this model all unobserved time invariant heterogeneity is captured by the individual effect that is also used to compute the level of efficiency (Greene, 2005a). A problem encountered with the RE model is that any time-invariant, firm-specific unobserved heterogeneity is considered as inefficiency. As a result, the scores obtained by this model are not accurate and tend to underestimate the level of persistent efficiency in hotels. In practice, this conclusion is reflected in the fact that persistent efficiency in the RE model is lower than in the GTRE model. 
The situation is improved somewhat with the TRE model, which controls for unobserved variables that are constant over time. However, any time-invariant component of inefficiency is captured by the firm-specific constant terms. Therefore, the TRE model tends to overestimate the level of efficiency and to provide information on the time-varying part of the inefficiency. As shown in Table 3, transient efficiency is slightly higher with the TRE model than with the GTRE model.

Focusing on the GTRE results, Table 3 shows that the average persistent efficiency $(82.51 \%)$ is higher than that of transient efficiency $(76.32 \%)$. Specifically, values of $24 \%$ and $17 \%$ were obtained for transient inefficiency (nonsystematic management problems) and persistent inefficiency (systematic management problems), respectively. ${ }^{8}$ These findings suggest that the output vector actually produced during the period analyzed could have been achieved with cost savings of $17 \%$ if systematic inefficiency were eliminated and of $24 \%$ without nonsystematic inefficiency.

Two remarkable aspects become apparent on comparing our results for the Canary Islands, obtained using SF and separating cost efficiency into its transient and persistent components, with those reported previously in studies of cost efficiency in other areas. On the one hand, Pérez-Rodríguez and AcostaGonzález (2007) also focused on the Canary Islands, and obtained an average transient inefficiency of $17 \%$, compared with the $24 \%$ we report. We explain this difference as follows: first, Pérez-Rodríguez and Acosta-González (2007) focused on the lodging industry in the island of Gran Canaria (one of the main destinations in the Canary Islands), and their data referred to different types of lodging (hotels, aparthotels, and apartments). Second, their econometric method (the Battesse and Coelli [1995] model) did not take account of the possible bias arising from unobserved heterogeneity, in turn caused by persistent inefficiency. Finally, the sample period analyzed (1991-2002) is immediately prior to the one considered in the present study. These two periods were strongly differentiated by the financial crisis that began in 2008, an event which in itself could have provoked a significant increase in transient inefficiency. At any event, these levels of cost inefficiency, in both cases, are high in comparison with other industries. For example, Filippini, Geissmann, et al. (2018) estimated average values of $8.0 \%$ for cost transient inefficiency and $13.8 \%$ for persistent inefficiency during the period 2000-2013 for hydropower firms in Switzerland. Similarly, Filippini, Greene, et al. (2018) estimated average values of around $12 \%$ for both persistent and transient cost inefficiencies for 2000-2011 using data for electricity distribution businesses in New Zealand. In view of these significant differences, it seems that managers can and should work to reduce the currently high levels of transient and persistent cost inefficiency in the Canary Islands hotel industry.

Another interesting aspect of the results obtained is the time-trend of the two efficiencies. To illustrate the empirical distribution of cost efficiencies over time, Figure 2 shows the year-by-year boxplot, summarizing the distribution of 


\section{Figure 2}

Time-Path for the Distribution of Estimated Cost Efficiencies: (a) Transient Cost Efficiency and (b) Persistent Cost Efficiency

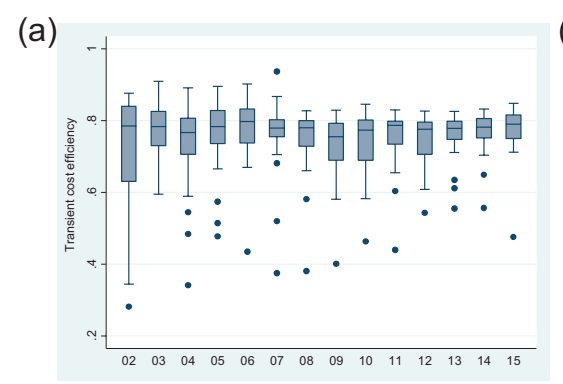

(b)

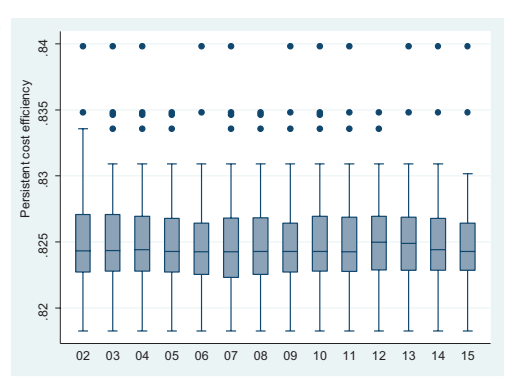

the transient (Figure 2a) and persistent (Figure 2b) efficiency values. This figure represents quartiles one and three. The difference between them is the interquartile range (the central $50 \%$ of the cost efficiency data). The line through the center of the box depicts the median, and the data points outside the inner fence are outliers. Significantly, the period analyzed spans various subperiods of crisis: the U.S. subprime crisis (2007-2008), the global financial crisis (2008-2010) and the sovereign debt crisis (2010-2012). During this period, too, the Spanish economy entered a recession (in the first quarter of 2012, the second Spanish economic downturn) and a major restructuring of the banking industry took place, following the bailout of the Spanish banking system in 2012 via the $€ 100$ billion rescue package provided by the European Stability Mechanism. All of these factors are potentially relevant to the performance of the Canary Islands lodging industry.

Figure $2 \mathrm{a}$ shows that the interquartile rank for transient efficiency (i.e., the dispersion of estimated cost efficiencies) decreased from 2003, and more sharply from 2007, with the exception of the periods 2009-2010 (the global financial crisis) and 2012 (the sovereign debt crisis). Moreover, the mean transient efficiency values increased (albeit slightly, from 0.72 to 0.77 ) between 2002 and 2015. On the other hand, the median values did not vary significantly (rising only from 0.78 in 2002 to 0.79 in 2025). In general, the cost efficiency of these hotels appears to be resilient to negative economic shocks. Our findings support those of Sellers-Rubio and Casado-Díaz (2018) for efficiency and of Cordero and Tzeremes (2017) and Tzeremes $(2019,2020)$ for productivity. Specifically, Sellers-Rubio and Casado-Díaz (2018) indicated that the efficiency scores for Canary Islands hotels rose between 2008 and 2016. On the other hand, with regard to persistent efficiency (Figure 2b), both the interquartile rank and the median remained constant during the period considered. In summary, we have robust empirical evidence that for these hotels persistent cost efficiency neither increased nor decreased very strongly between 2002 and 2015. Hence, the crises that occurred during the corresponding subperiods did not affect persistent 
efficiency, indicating that systematic management problems were not resolved in this period and that structural problems remained in the industry.

Finally, it should be noted that the correlation of cost efficiencies between TRE and GTRE models is very high (90\%). However, according to Filippini and Greene (2016), given that TRE is highly correlated with the transient efficiency of the GTRE model, the TRE model tends to estimate the transient part of efficiency. Moreover, the TRE model is preferred to the RE model because $\sigma_{w}$ is statistically significant at 5\%. The correlation between RE and GTRE is close to $40 \%$.

\section{Time-Varying (Transient) Cost Efficiency and Its Determinants}

Unfortunately, the GTRE model of Filippini and Greene (2016) does not allow us to include environmental variables to explain transient and persistent efficiency. ${ }^{9}$ As the latter presents only slight variation (the standard deviation is 0.0043), in this study, we focus on the TRE model, in contrast to the approach taken by Barros et al. (2010), Assaf and Tsionas (2018) and Arbelo et al. (2020, 2021).

Although persistent efficiency was not modelled, and so the results obtained might be subject to bias, we obtained a simultaneous estimate of the parameters of the stochastic translog cost frontier panel data, separating unobserved heterogeneity from inefficiency, and including a set of observed environmental variables (i.e., hotel-specific variables) to incorporate the variables that might affect transient efficiency. This approach, therefore, avoids the use of a biased two-step procedure.

Under the TRE-NTN specification, $u_{i t}$ cannot have a zero mean because it is present in equation [1]. More specifically, this inefficiency term is assumed to be distributed as $u_{i t} \sim N^{+}\left(\mu_{i}, \sigma_{u}^{2}\right)$, where $\mu_{i}=\beta^{\prime} z_{i}, z_{i}$ is a vector of covariates and $\beta$ is a vector of unknown parameters.

Supplemental Table S2 shows the results for the stochastic translog cost frontier and the determinants of the transient cost efficiency estimates, as obtained from the TRE-NTN model. This approach could offer important information for policy makers and hotel managers about short-term implications for the industry (e.g., enabling hotel managers to focus on areas where immediate attention is necessary to improve business performance).

The following covariates were used as determinants of mean inefficiency: market share (size), degree of independence ( $50 \%$ or more of firm ownership by a single shareholder), experience, number of subsidiaries, crisis period, island location. The vectors of the covariates considered are shown in Table 1, together with those of the following variables: island location, global ultimate owner (categorized as one or more named individuals or families, corporate, financial company, bank, and others) and immediate shareholder (\%). However, inclusion of the latter affected the convergence of our models and so they were excluded from the analysis. 
In general, the results shown in Supplemental Table S2 (available online) corresponding to the TRE-NTN model suggest that cost efficiency, too, is time varying and that unobserved heterogeneity is present, indicating possible nonsystematic management problems. Mean transient efficiency is slightly higher than in the GTRE model, indicating overestimation of the average efficiency, given that there is persistent efficiency (as shown in section 5.2). As in the case of the TRE, although the TRE-NTN model has an RTS value of less than one, the null hypothesis of RTS $=1$ is not rejected. Regarding the determinants of efficiency, we conclude that the crisis period did not affect cost efficiency, and that the sector remained stable during this period. On the other hand, accumulated experience or knowledge has a positive impact on cost efficiency. This conclusion is consistent with the theory of learning-by-doing (the learning curve). For the proxies associated with heterogeneity in the Canary Islands hotel industry (i.e., size and ownership), we find that both market share and degree of independence have a positive effect on cost efficiency. Finally, the number of subsidiaries is statistically significant, producing a negative effect on efficiency.

Supplemental Figure S1 (available online) shows the transient cost efficiencies and the evolution of the empirical distributions year-by-year. Within it, the histogram estimates for the overall cost efficiencies (similar to those shown in Figure 1a) are plotted in S1a, while S1b shows the year-by-year boxplot. As can be seen, transient cost efficiency increased slightly over time (with median efficiency values rising from 0.855 to 0.897 during the period 2002 to 2015 , with the sole exception of the years 2007-2009, when the values fell slightly). This suggests that hotel performance improved slightly per period and that economic interests were efficiently managed. The overall increase was around $5 \%$ and the crisis subperiods had no notable effect on cost efficiency.

Although the present analysis does not allow us to explain the two types of inefficiency, it can be concluded that factors accounting for short-term management performance include market share, the number of subsidiaries, experience and the degree of independence. We found no evidence that the global economic crisis affected transient inefficiency.

\section{CONCLUSIONS}

This article extends the existing literature by providing more accurate estimates of hotel efficiency, in which unobserved heterogeneity is distinguished from the transient and persistent components of efficiency. Transient elements may indicate nonsystematic management problems (which can be addressed and resolved immediately), while the persistent aspect of efficiency might be related to the presence of systematic shortcomings in managerial capabilities or of structural problems in the organization of the production process. The neglect of persistent/transient efficiency and unobserved heterogeneity is likely to lead to inconsistent parameter estimates being obtained for a panel data SF model. 
In this context, our study focuses on two main aspects of the question. First, we investigate hotel cost efficiency using the stochastic translog cost frontier specification and the GTRE model of Filippini and Greene (2016), a four-random-component SF model which allows us to estimate persistent and transient inefficiencies separately from unobserved heterogeneity. Second, we conduct an empirical analysis based on data for the hotel industry in the Canary Islands (Spain), which is a major sun-and-beach destination for European travelers, referring to the period 2002 to 2015 (annual data). The following main results were obtained.

On the one hand, the presence of not only transient and persistent cost inefficiencies, but also of unobserved heterogeneity was detected. For this reason, the GTRE specification was statistically significant. The GTRE model predicts that during the study period from 2002 to 2015 the Canary Islands hotel industry could have achieved a $17 \%$ cost saving by overcoming systematic inefficiency (the persistent part) and a further $24 \%$ cost saving by eliminating nonsystematic inefficiency (the transient part). In addition, transient inefficiency (i.e., that which could be interpreted in the context of a given year) was higher than persistent inefficiency, which could be interpreted as meaning there would be fewer operational problems in the long term. These two components of inefficiency differ in their interpretation and implications, but together they inform managers of the firm's position with respect to its local or industry competitors. Furthermore, from the perspective of an individual establishment, the two types of cost inefficiency might require management to analyze the hotel's internal activities: procurement, technology, products and services, human resources and infrastructure, and to respond appropriately, applying strategies for improvement, identifying areas of weaknesses associated with each type of inefficiency and formulating strategies for future implementation. In addition, it would be helpful if hotel managers could determine whether the seasonal nature of their business affected inefficiency (transient and/or persistent). Seasonality affects both the costs of resource inputs and the prices paid by consumers.

In addition, we analyze the determinants of transient cost efficiencies in an unobserved-heterogeneity TRE framework, as proposed by Greene (2005a), taking into account that persistent and transient cost inefficiencies cannot be considered jointly due to the slightness of variations in persistent efficiency. Our study of the determinants of time-varying cost inefficiency in the TRE model revealed that average transient cost efficiency increased slightly over time and that the economic and financial crisis did not affect the hotel sector. In addition, heterogeneity among hotels and differences in production (cost) technologies are generated by environmental factors such as size (market share), degree of independence, experience (or the age of the hotel), and the number of subsidiaries. All of these factors are relevant to transient cost efficiency and contributed to reducing inefficiency in the Canary Islands lodging sector during the period 2002-2015. With regard to market size, policy makers might address the impact of scale on hotel productivity by focusing on larger hotels. However, in our analysis the number of 
subsidiaries was positively associated with inefficiency, and therefore measures are needed to remove this source of transient inefficiency.

The method and results presented in this article have certain interesting theoretical and policy implications, as we discuss next.

Among the theoretical implications of our work, this article provides an overview of the GTRE SF model as a means of separating overall hotel cost efficiency into transient and persistent cost efficiency, and of distinguishing unobserved heterogeneity from cost efficiency, thereby providing a rigorous measure of performance. Application of the method we describe could help managers identify hotels which present nonsystematic and (potentially) systematic management problems, not only enabling these hotels to be ranked but also determining the impact of any unobserved heterogeneity.

As concerns policy implications, the most important is the fact that the methods described enable us to distinguish transient from persistent efficiency, making it possible to assess hotel performance in terms of levels of management responsibility.

Transient efficiency varies over time and consideration of this question can help hotel policy makers respond appropriately to year-by-year changes. For example, goals might be set to achieve better short-term returns through higher factor productivity and incentives provided to raise short-term efficiency (e.g., by $2 \%$ within $2-3$ years); or a suitable response could be made to the variation in visitor numbers in a given year; or annual strategies could be devised for revenue and budget management (e.g., by optimizing revenue according to demand, creating appropriate pricing strategies and/or analyzing the industry competition, among other possibilities).

On the other hand, persistent efficiency is a constant factor. Consideration of this question can enable policy makers to establish a hotel-specific structure, thus optimizing structural efficiency (e.g., by setting long-term goals based on infrastructure improvements and responding to institutional regulation of the sector). Positive long-term outcomes can be obtained by addressing questions of persistent efficiency, applying strategies based on a longer time horizon. Policy makers might address this area of the business in various ways, for example, by introducing incentives to improve efficiency over a substantial period (such as 8-10 years); by adopting as a competitive strategy the accumulation of knowledge, viewing this as a strategic resource with which to increase efficiency; by taking advantage of advances in hotel technologies or by renovating the hotel's physical organization; and/or by considering fundamental industry factors such as the long-term growth of hotels or the type of ownership that would increase efficiency.

The tourism sector is highly dependent on policy makers' decisions, insofar as the firms involved make use of resources they neither own nor control, such as port and airport infrastructure and urban environments in tourist areas. This lack of ownership and control of resources highlights the interdependence among organizations operating in the tourism industry. In the Canary Islands in 
particular, it is important for the public and private sectors to join forces to regenerate currently decaying areas that were first exploited by the tourism industry in the 1960s, 1970s, and 1980s. By improving the quality of the Canary Islands as a tourist destination, with respect to its direct competitors, hotels can increase their efficiency by attracting clients with greater purchasing power. Attention to these questions would make hotels less vulnerable to changing economic conditions in both the short and the long term.

Certain limitations to the present study should be acknowledged. First, although the study period is extensive (2002-2015), it would be useful in future research to expand this time interval and, moreover, to analyze the impact produced by the hotel construction moratorium ordered in the Canary Islands. In addition, a wider range of inputs and outputs should be included, together with more hotel-specific determinants in the analysis (addressing factors such as obsolete machinery and equipment, rigidities in the workforce and gaps in administrative activities). The fact that we were unable to study the determinants of persistent and transient inefficiency simultaneously is another limiting factor. Finally, future research should be undertaken to develop models capable of separating hotel efficiency into its transient and persistent components, in which the "same production technology" assumption considering random coefficients can be relaxed.

\section{ORCID iD}

Jorge V. Pérez-Rodríguez (iD https://orcid.org/0000-0002-6738-9191

\section{SUPPLEMENTAL MATERIAL}

Supplemental material for this article is available online.

\section{NOTES}

1. In this article, transient efficiency is assumed to be equivalent to nonsystematic, transitory, temporary, or short-run efficiency, in other words, time-varying. In contrast, persistent or time-invariant efficiency is that which is permanent or systematic, and present in the long term. Moreover, time-invariant efficiency should be distinguished from unobserved heterogeneity.

2. In the GTRE model, the error term is split into four components. The first reflects a firm's latent heterogeneity, the second represents long-run (systematic, persistent, or time-invariant) inefficiency, the third captures short-run (nonsystematic, transient, or time-varying) inefficiency, and the fourth describes random shocks.

3. The GTRE model of Filippini and Greene (2016) is an extension of the true random effects (TRE) model (Greene, 2005a, 2005b), which reflects the unobserved heterogeneity component (captured by a random effect [RE]) together with a transient inefficiency term.

4. The term extra-hotel is used in a broad sense to mean establishments that offer tourist accommodation together with other services (or in the case with private homes, do not). Establishments in this category include tourist apartments, campsites, rural tourism accommodation, hostels, and private homes. 
5. Rehabilitation projects that would upgrade any establishment without increasing the number of beds were also excluded from the rule.

6. The number of years a company has been in business can be a good indicator of its experience or accumulation of experience (Bernini \& Guizzardi, 2010).

7. Another model proposed by Greene (2005a), termed the true fixed effect model, could be used. However, this approach can result in biased inefficiency estimates, as a consequence of incidental parameters. To overcome this problem, the TRE and GTRE models are used as alternative estimation procedures.

8. These figures were calculated from the transient and persistent efficiency estimates shown in Table 3. Specifically, $24=(1-0.76) \times 100$ and $17=(1-0.83) \times 100$.

9. Although Colombi et al. (2017) presented an extension of the Colombi et al. (2014) maximum log likelihood estimation method for the four-random-component closed skew-normal SF model, with the inclusion of exogenous determinants of persistent (long-run) and transient (short-run) inefficiency, distinct from unobserved heterogeneity, we were unable to apply this model successfully due to the slight variation in persistent inefficiency.

\section{REFERENCES}

Agasisti, T., \& Gralka, S. (2019). The transient and persistent efficiency of Italian and German universities: A stochastic frontier analysis. Applied Economics, 51(46), 5012-5030. https://doi.org/10.1080/00036846.2019.1606409

Arbelo, A., Arbelo-Pérez, M., \& Pérez-Gómez, P. (2020). Technological heterogeneity and hotel efficiency: A Bayesian approach. Cornell Hospitality Quarterly, 61(2), 170-182. https://doi.org/10.1177/1938965519889286

Arbelo, A., Arbelo-Pérez, M., \& Pérez-Gómez, P. (2021). Heterogeneity of resources and performance in the hotel industry. Journal of Hospitality \& Tourism Research, 45(1), 68-89. https://doi.org/10.1177/1096348020944450

Arbelo, A., Pérez-Gómez, P., \& Arbelo-Pérez, M. (2017). Cost efficiency and its determinants in the hotel industry. Tourism Economics, 23(5), 1056-1068. https://doi. org/10.1177/1354816616656419

Arbelo, A., Pérez-Gómez, P., González-Dávila, E., \& Rosa-González, F. M. (2017). Cost and profit efficiencies in the Spanish hotel industry. Journal of Hospitality \& Tourism Research, 41(8), 985-1006. https://doi.org/10.1177/1096348015587999

Assaf, A. G., Barros, C. P., \& Josiassen, A. (2010). Hotel efficiency: A bootstrapped metafrontier approach. International Journal of Hospitality Management, 29(3), 468-475. https://doi.org/10.1016/j.ijhm.2009.10.020

Assaf, A. G., \& Magnini, V. (2012). Accounting for customer satisfaction in measuring hotel efficiency: Evidence from the US hotel industry. International Journal of Hospitality Management, 31(3), 642-647. https://doi.org/10.1016/j.ijhm.2011.08.008

Assaf, A. G., \& Josiassen, A. (2016). Frontier analysis: A state-of-the-art review and meta-analysis. Journal of Travel Research, 55(5), 612-627. https://doi.org/10.1177 /0047287515569776

Assaf, A. G., \& Tsionas, M. (2018). Measuring hotel performance: Toward more rigorous evidence in both scope and methods. Tourism Management, 69(December), 69-87. https://doi.org/10.1016/j.tourman.2018.05.008

Barros, C. P. (2004). A stochastic cost frontier in the Portuguese hotel industry. Tourism Economics, 10(2), 177-192. https://doi.org/10.5367/000000004323142416 
Barros, C. P., Dieke, P., \& Santos, C. A. (2010). Heterogeneous technical efficiency of hotels in Luanda, Angola. Tourism Economics, 16(1), 137-151. https://doi.org/10.5367 /000000010790872178

Barros, C. P., Peypoch, N., \& Solonandrasana, B. (2009). Efficiency and productivity growth in hotel industry. International Journal of Tourism Research, 11(4), 389-402. https://doi.org/10.1002/jtr.711

Battese, G., \& Coelli, T. (1992). Frontier production functions, technical efficiency and panel data: With application to paddy farmers in India. Journal of Productivity Analysis, 3(1), 153-169. https://doi.org/10.1007/BF00158774

Battese, G., \& Coelli, T. (1995). A model for technical inefficiency effects in a stochastic frontier production function for panel data. Empirical Economics, 20(2), 325-332. https://doi.org/10.1007/BF01205442

Bernini, C., \& Guizzardi, A. (2010). Internal and locational factors affecting hotel industry efficiency: Evidence from Italian business corporations. Tourism Economics, 16(4), 883-913. https://doi.org/10.5367/te.2010.0008

Chen, C. F. (2007). Applying the stochastic frontier approach to measure hotel managerial efficiency in Taiwan. Tourism Management, 28(3), 696-702. https://doi.org /10.1016/j.tourman.2006.04.023

Christie \& Co. (2016). The Canary Islands hotel market. https://www.christie.com/ christieMediaLibraries/christie/PDFs-Publications/Hotels/ChristieCo-CanaryIslands-Hotel-Market.pdf?ext=.pdf

Colombi, R. (2010). A skew normal stochastic frontier model for panel data. Proceedings of the 45th scientific meeting of the Italian statistical society, Padua, Italy.

Colombi, R., Kumbhakar, S. C., Martini, G., \& Vittadini, G. (2014). Closed-skew normality in stochastic frontiers with individual effects and long/short-run efficiency. Journal of Productivity Analysis, 42(2), 123-136. https://doi.org/10.1007/s11123014-0386-y

Colombi, R., Martini, G., \& Vittadini, G. (2011). A stochastic frontier model with short-run and long-run inefficiency random effects. Department of Economics and Technology Management, Universita Di Bergamo, Italy.

Colombi, R., Martini, G., \& Vittadini, G. (2017). Determinants of transient and persistent hospital efficiency: The case of Italy. Health Economics, 26(S2), 5-22. https://doi. org/10.1002/hec.3557

Cordero, J. M., \& Tzeremes, N. G. (2017). Evaluating hotel productivity growth in Balearic and Canary Islands. Tourism Economics, 23(5), 1146-1154. https://doi.org $/ 10.1177 / 1354816616683051$

Cornwell, C., Schmidt, P., \& Sickles, R. (1990). Production frontiers with cross-sectional and time-series variation in efficiency levels. Journal of Econometrics, 46(1-2), 185-200. https://doi.org/10.1016/0304-4076(90)90054-W

Filippini, M., Geissmann, T., \& Greene, W. H. (2018). Persistent and transient cost efficiency: An application to the Swiss hydropower sector. Journal of Productivity Analysis, 49(1), 65-77. https://doi.org/10.1007/s11123-017-0522-6

Filippini, M., \& Greene, W. (2016). Persistent and transient productive inefficiency: A maximum simulated likelihood approach. Journal of Productivity Analysis, 45(2), 187-196. https://doi.org/10.1007/s11123-015-0446-y

Filippini, M., Greene, W. H., \& Masiero, G. (2018). Persistent and transient productive inefficiency in a regulated industry: Electricity distribution. Energy Economics, 69(January), 325-334. https://doi.org/10.1016/j.eneco.2017.11.016 
FRONTUR. (2017). Entradas de turistas desde el extranjero según comunidades autónomas de destino principal por periodos [Tourist entries from abroad according to autonomous communities of main destination by periods]. http://www.gobiernodecanarias.org/istac/jaxi-istac/tabla.do?uripx=urn:uuid:a4f8d3ed-fffc-4f58-b0bf-6ea6d2a b3d54\&uripub=urn:uuid:ccdf465c-2230-421d-99f6-d6a1669d6032

Greene, W. (2005a). Reconsidering heterogeneity in panel data estimators of the stochastic frontier model. Journal of Econometrics, 126(2), 269-303. https://doi.org/10.1016 /j.jeconom.2004.05.003

Greene, W. (2005b). Fixed and random effects in stochastic frontier models. Journal of Productivity Analysis, 23(1), 7-32. https://doi.org/10.1007/s11123-004-8545-1

Inchausti-Sintes, F., \& Voltes-Dorta, A. (2020). The economic impact of the tourism moratoria in the Canary Islands 2003-2017. Journal of Sustainable Tourism, 28(3), 394-413. https://doi.org/10.1080/09669582.2019.1677677

Instituto Canario de Estadística. (2017). Encuestas de Alojamiento Turístico [Tourist accommodation surveys]. http://www.gobiernodecanarias.org/istac/jaxi-istac/menu. do?uripub=urn:uuid:40dab52d-bc0e-4986-969c-05d6b9260959

Instituto Nacional de Estadística. (2017). Contabilidad regional de España [Regional accounting of Spain]. https://www.ine.es/index.htm

Jondrow, J., Lovell, C. A. K., Materov, I. S., \& Schmidt, P. (1982). On the estimation of technical inefficiency in the stochastic frontier production function model. Journal of Econometrcis, 19(2-3), 233-238. https://doi.org/10.1016/0304-4076(82)90004-5

Kim, S. (2011). Factor determinants of total factor productivity growth in the Malaysian hotel industry: A stochastic frontier approach. Cornell Hospitality Quarterly, 52(1), 35-47. https://doi.org/10.1177/1938965509341286

Kumbhakar, S. C. (1990). Production frontiers, panel data and time-varying technical inefficiency. Journal of Econometrics, 46(1-2), 201-212. https://doi.org/10.1016 /0304-4076(90)90055-X

Kumbhakar, S. C. (1991). The measurement and decomposition of cost-inefficiency: The translog cost system. Oxford Economic Papers, 43(4), 667-683. https://doi.org /10.1093/oxfordjournals.oep.a042023

Kumbhakar, S. C., \& Heshmati, A. (1995). Efficiency measurement in Swedish dairy farms: An application of rotating panel data. American Journal of Agricultural Economics, 77(3), 660-674. https://doi.org/10.2307/1243233

Kumbhakar, S. C., \& Hjalmarsson, L. (1993). Technical efficiency and technical progress in Swedish dairy farms. In H. O. Fried, C. K. Lovell, \& S. S. Schmidt (Eds.), The measurement of productive efficiency. Techniques and applications (pp. 226-270). Oxford University Press.

Kumbhakar, S. C., \& Hjalmarsson, L. (1995). Labour-use efficiency in Swedish social insurance offices. Journal of Applied Econometrics, 10(1), 33-47. https://doi.org /10.1002/jae.3950100104

Kumbhakar, S. C., Lien, G., \& Hardaker, J. B. (2014). Technical efficiency in competing panel data models: A study of Norwegian grain farming. Journal of Productivity Analysis, 41(2), 321-337. https://doi.org/10.1007/s11123-012-0303-1

Kumbhakar, S. C., Parmeter, C. F., \& Tsionas, E. G. (2013). A zero inefficiency stochastic frontier model. Journal of Econometrics, 172(1), 66-76. https://doi.org/10.1016/j. jeconom.2012.08.021

Lee, Y., \& Schmidt, P. (1993). A production frontier model with flexible temporal variation in technical inefficiency. In H. O. Fried, C. A. K. Lovell, \& S. S. Schmidt 
(Eds.), The measurement of productive efficiency: Techniques and applications (pp. 237-255). Oxford University Press.

Pérez-Rodríguez, J. V., \& Acosta-González, E. (2007). Cost efficiency of the lodging industry in the tourist destination of Gran Canaria (Spain). Tourism Management, 4(4), 993-1005. https://doi.org/10.1016/j.tourman.2006.08.007

Pitt, M., \& Lee, L. (1981). The measurement and sources of technical inefficiency in Indonesian weaving industry. Journal of Development Economics, 9(1), 43-64. https://doi.org/10.1016/0304-3878(81)90004-3

Reynolds, D. (2003). Hospitality productivity assessment using data envelopment analysis. Cornell Hotel and Restaurant Administration Quarterly, 44(2), 130-138. https://doi.org/10.1177/0010880403442012

Schmidt, P., \& Sickles, R.C. (1984). Production frontiers and panel data. Journal Business and Economics Statistics, 2(4), 367-374. https://doi.org/10.1080/07350015 .1984 .10509410

Sellers-Rubio, R., \& Casado-Díaz, A. B. (2018). Analyzing hotel efficiency from a regional perspective: The role of environmental determinants. International Journal of Hospitality Management, 75(September), 75-85. https://doi.org/10.1016/j.ijhm.2018 .03 .015

Tsionas, E. G. (2002). Stochastic frontier models with random coefficients. Journal of Applied Econometrics, 17(2), 127-147. https://doi.org/10.1002/jae.637

Tsionas, E. G., \& Kumbhakar, S. C. (2014). Firm heterogeneity, persistent and transient technical inefficiency: A generalized true random-effects model. Journal of Applied Econometrics, 29(1), 110-132. https://doi.org/10.1002/jae.2300

Tzeremes, N. G. (2019). Hotel productivity: A robust Luenberger productivity indicator. Tourism Economics, 25(6), 987-996. https://doi.org/10.1177/1354816618821271

Tzeremes, N. G. (2020). Robust Malmquist productivity measurement: Evidence from Spanish hotel industry during the Great Recession. International Journal of Productivity and Performance Management, 70(2), 408-426. https://doi.org/10.1108/ IJPPM-01-2019-0037

\section{Submitted February 23, 2019 \\ Accepted June 24, 2021 \\ Refereed Anonymously}

Jorge V. Pérez-Rodríguez (e-mail: jv.perez-rodriguez@ulpgc.es) is Professor of Econometrics at Department of Quantitative Methods (University of Las Palmas de Gran Canaria, Spain). His research focuses on the tourism economics and financial statistics and econometrics. He has widely published in peer-reviewed international journals on these topics, such as Tourism Management, Annals of Tourism Research, Tourism Economics, World Economy, Empirical Finance, Quantitative Finance, Journal of Productivity Analysis, Economic Modelling, Empirical Economics, among others. Eduardo AcostaGonzález (e-mail: eduardo.acosta@ulpgc.es) is Professor of Econometrics and Statistics (University of Las Palmas de Gran Canaria, Spain). His research focuses on the tourism economics and financial statistics and econometrics. He has widely published in peerreviewed international journals on these topics, such as Tourism Management, Quantitative Finance, Empirical Economics, Applied Economics, among others. 